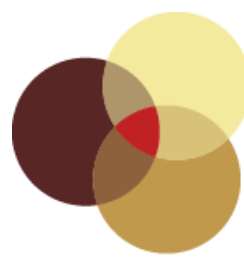

\title{
Mapping Collected Memory An Exploration of Memory-Based Navigation in Amman, Jordan
}

Regina Mamou

\begin{abstract}
The purpose of this research is to explore navigational and image-making methods in a context where maps and formal address systems have been minimally consulted in recent years. This investigation is approached by way of a research-based art project on subjective cartography, which was carried out from 2009 to 2010 during a Fulbright fellowship to Amman, Jordan. The project examines the mutability of a specific location as well as its relationship between obsolescence in cartographic resources and the photographic medium. By reaching out to Ammani residents for informal tours of the city, selected guides were asked to narrate their experiences of navigating the city by memory and then directed to point out key landmarks during this process. Later, these tours were re-memorized and landmarks were photographed as a representation of the afterimage to capture high-quality still images through the use of a large-format photographic device. These afterimages are not intended to serve as documents or memorials of Amman but rather as ruminations on the faculties of memory in an ever-changing environment. This subjective experience, or the observation of a city's minutiae amid wayfinding, poses a series of inquiries, vis-à-vis memory-based navigation and the role of still images, as an alternative to the panoptic view of a map. The result is a meditative project considering the plasticity of an urban entity, presented as a composition of written material and large-scale photographs, fragments of the city that when viewed as a series come together as a constellation of a subjective whole.
\end{abstract}

\section{About the Author}

Regina Mamou is a Chicago-based visual artist working at the intersection of photography, installation, writing, and research practices. She has exhibited her work nationally and internationally. Mamou holds an MFA from the School of the Art Institute of Chicago and a BFA from the Rhode Island School of Design. 


\section{Mapping Collected Memory}

\section{An Exploration of Memory-Based Navigation in Amman, Jordan}

\author{
Regina Mamou
}

A cartographic resource, whether analog or digital, is subject to inevitable obsolescence, which leads to revision or mutability over time. By identifying known and used landmarks throughout a city, which aid in wayfinding, a resident or visitor is able to criss-cross metropolitan areas utilizing an abstract, fluid, and personalized method. Broadly speaking, the city is a plastic entity, which is ever more apparent in globalization, especially in locations experiencing vast migrational patterns. While physical landmarks used by residents, visitors, and travelers are liable to change at the hand of urbanization and construction, especially in a contemporary environment, the memory of cultural, social, and historical urban markers is often permanently incorporated in the general lexicon of a city.

Appropriately, then, the purpose of this research-based art project is to explore landmarks in the context of Amman, Jordan, a locality where maps and formal address systems are minimally consulted in everyday travel, while examining specific markers and the means by which they are memorized, imaged, and interpreted in regard to navigation. The project explores image-based representation, with the utilization of wayfinding systems, as a metaphorical interpretation of a contemporary city, in addition to considering issues of architecture, urban planning, and population growth. Concerning itself primarily with conceptual forms of mapping, or what the contemporary geographer Denis Cosgrove describes as "'mapping,' the cognitive and creative process rather than the scientific and design aspects of map-making," the project seeks an avenue to discuss the psychology of the city through experiential travel using the eclectic elements of writing, photography, video, and durational performance (i.e., walking and driving tours) to interpret and present the findings of traversing a contemporary environment. ${ }^{1}$

As opposed to interpreting a lack of map usage as a pejorative concept, this project investigates a central theme: memory-based navigation using verbal narration inherently grants a traveler a better understanding of the city. For Amman, a place that utilizes a landmark-dominated navigational system, landmarks differ from person to person, and these markers are dependent on one's relationship to and within the city, as well as one's knowledge of a particular neighborhood through a non-linear perspective of its wayfinding system. In formal map production, interpretation and subjective cartography is lost in the process.

A version of this paper was delivered at The Mediated City conference organized by the scholarly journal Architecture_MPS, London, April 1-3, 2014.

${ }^{1}$ Denis Cosgrove, Geography and Vision: Seeing, Imagining and Representing the World (London: I.B.Tauris and Co., 2008), 68. Cosgrove's book provides dynamic essays, mixing metaphor and history, on the relationship between the landscape, space, and human activity. The fourth chapter, "Mapping Arcadia," is of particular interest to this project in regard to the figurative interpretations of geography. 


\section{Methods and Tools Utilized in the Research-Based Art Project}

The project research and images were developed over a fifteen-month period from September 2009 to December 2010 during a Fulbright US Student Program grant to Amman, Jordan. $^{2}$ The methodology used in collecting material to create Mapping Collected Memory: An Exploration of Memory-Based Navigation in Amman, Jordan, which is first and foremost a research-based art project, is an abstract approach derived from the seminal text of Kevin Lynch's The Image of the City (1960). ${ }^{3}$ The project involved reaching out to residents of Amman for walking and driving tours of the metropolis.

Makan Art Space, a non-profit contemporary art center in Amman, Jordan, kindly sent out a call for participation electronically in English with a translated letter in Arabic. This electronic medium garnered a specific demographic of participants: a group of approximately ten permanent residents, as well as temporary visitors, who were either artists or familiar with Makan's programming, and who were comfortable meeting for an informal walk or drive through the city. Participants were asked to select a navigational process (via pedestrian or vehicular travel) and a route that they used in quotidian activities. On these tours, guides narrated their experience of navigating the city using visual and verbal cues, without the aid of a map, and were directed to point out key landmarks in their navigational process. The tours were also captured via a digital camera for documentation purposes. After memorizing routes with guides during the in-person tours, landmarks were photographed later as a representation of the afterimage, capturing high-quality still images through the use of a large-format photographic device, specifically a four-by-five-inch monorail camera. The final result is a presentation composed of written material, large-scale photographs, and moving images of the process: fragments of the city that when viewed as a complete project come together as a constellation of a subjective whole.

The project is not intended to document the experience of navigation, but rather ruminate on the practice of memorizing the city through its navigational methods. It deemphasizes the importance of the map and its systems, instead placing emphasis on the concept of how a city is traversed, particularly one in transition, through the experiential learning of memory and its routes. The images in the portfolio, presented at the end of this written account and research, are not intended to serve as a guidebook, historical reference, cartographic resource, or memorialization of these ever-changing markers. Rather, they should be seen as the final visual conceptualization and metaphorical interpretation of one particular contemporary city, produced via a research-based art practice, and what Trevor

\footnotetext{
${ }^{2}$ While I am speaking about my own project, for purposes of this formal written account, there is a conscious decision to suppress a first-person narration and refer to the work using an abstract voice.

${ }^{3}$ Lynch outlines a methodology in the appendix B entitled "The Use of the Method," which details the manner by which a sample of citizens were interviewed for the purpose of imaging Los Angeles, Boston, and Jersey City. Individuals responded to a series of questions in relation to city routes and the memorization of particular areas of each metropolis. Kevin Lynch, The Image of the City (Cambridge, MA: MIT Press, 1960), 140-159.
} 
Paglen has termed "experimental geography," to describe the engagement with space as a fluid and experiemental practice. ${ }^{4}$

\section{Amman's History: Interpretations on a Lack of Map Usage}

What makes Amman, the capital city of the Hashemite Kingdom of Jordan, a singular city and unique locale for this research? In Urban Crossroads, a column that features regular articles by Mohammad al-Asad, the founding director of the Center for the Study of the Built Environment, in Amman, Jordan, al-Asad ruminates on various identifying characteristics of the city. ${ }^{5}$ Amman is described, by al-Asad, as a dense network of streets, difficult for a newcomer to maneuver. ${ }^{6}$ Despite a small production of maps, a number system to designate addresses, and street names-some more recently implemented than others-many of Amman's visitors and residents rely on personal methods to navigate the city. In this situation, the project asks the question, what is the benefit of a map if the urban environment is subjected to constant change? Coincidentally or not, citizens of Amman experience an "aversion to using street maps," as al-Asad commented in Urban Crossroads. ${ }^{7}$ In navigating Amman, there is an integration of formal and informal systems, which has enforced the memorization of the city's history and labeling systems.

People in Amman do not even use street names, except for the major streets of the city. Instead, they identify a street by some landmark . . . even for a number of major streets, the official name is not always used, but instead, a name based on a wellknown landmark located along it. ${ }^{8}$

There has been a plethora of studies in navigation, and, more specifically, how this relates to memory, from Ramallah to Cairo to Beirut, the latter of which will be addressed briefly. Memory and mapping practices are certainly not conceptually new to the global arena, and artists, as well as cultural historians, have tackled both topics, in a broader sense

\footnotetext{
${ }^{4}$ See Nato Thompson, Experimental Geography: Radical Approaches to Landscape, Cartography, and Urbanism, (New York: Independent Curators International, in association with Melville House, 2008 ), 13. Regarding the Independent Curators International exhibition, "Experimental Geography," Thompson comments: "The manifestations of 'experimental geography' (a term coined by geographer Trevor Paglen in 2002) run the gamut of contemporary art practice today." Independent Curators International Exhibitions, "Experimental Geography," accessed February 9, 2014, http://curatorsintl.org/exhibitions /experimental_geography.

${ }^{5}$ See the introductory web page of Urban Crossroads, which details the article's topics and publication dates. The introduction reads as follows: "Urban Crossroads is a regular column written by Mohammad alAsad, the founding director of the Center for the Study of the Built Environment (CSBE) in Amman. Its articles address issues relating to the urban built environment, with an emphasis on Amman and other cities in Jordan. The articles explore the various dynamics that shape our cities, including the physical, geographic, cultural, social, economic, and political, and examine how such dynamics may be harnessed to bring about improvements in the quality of urban life. The first Urban Crossroads article appeared in The Jordan Times, Jordan's English-language daily, on April 15, 2004, and continued to be published there until August 2011. Following that, it has been published through the online portals www.tareeq.me and www.7iber.com in both Arabic and English." Urban Crossroads, "Introduction," accessed February 9, 2014, http://www.csbe.org/e-publications-resources/urban-crossroads.

${ }^{6}$ Mohammad al-Asad, "Amman Street Maps: A New Frontier," Urban Crossroads 18 (September 9, 2004), accessed February 9, 2014, http://www.csbe.org/e-publications-resources/urban-crossroads /amman-street-maps-a-new-frontier.

${ }^{7}$ Ibid.

${ }^{8}$ Ibid.
} 
of the term, from pointed conferences to symposia in the Middle East and North Africa. ${ }^{9}$ For example, the Beirut-based artist Tony Chakar, who conducts ongoing historical walking tours to pinpoint narrative-based, neighborhood-centered descriptions of the city, explores this trend by imaging the metropolis through faculties of the past. ${ }^{10}$ On Chakar's website for The Sky Over Beirut (2009-), in the Historical City Tour section, he provides digital mapping points with narrative descriptions of specific areas in the city. In a poetic manner, one didactic text for a detailed area describes an individual's attempt to navigate to a specific point in Beirut.

The map I had was old and undated, so I got a new map from my hotel. I tried to compare the two maps, but the differences among them were huge. For a moment I thought that the map I brought with me was not of the same city. ${ }^{11}$

The notion of navigating without a formal cartographic resource and address system is a common practice in many cities throughout the regions of the Middle East and North Africa. The city of Amman is a relatively young metropolis with "the history of modern Amman dat[ing] back to the 1870s," and major building developments taking place within the last fifty years. ${ }^{12}$ This shift can be attributed to a gamut of characteristics, including foreign and domestic conflict, as well as assets that were obtained through oil in the 1970s and 1980s. ${ }^{13}$ Additionally, Jordan's first university opened in the 1960 s, pulling educators and students into the city's center. ${ }^{14}$ More specifically, this has caused urban progress to develop rather swiftly, stemming from "the 1948 and 1967 Arab-Israeli wars" and external conflict in neighboring countries. ${ }^{15}$ These "sudden spurts" have placed Amman in the unique

\footnotetext{
9 "Home Works 5: A Forum on Cultural Practices" was organized by the non-profit organization Ashkal Alwan, the Lebanese Association for Plastic Arts, based in Beirut, Lebanon. "Home Works 5" was held from April 21 to May 1, 2010, featuring a plethora of presentations, events, and artwork. Several of these works were focused on the practices of mapping and memory. See the "Home Works 5" brochure, accessed February 9, 2014, http://cdn.ashkalalwan.org/wp-content/uploads/2013/04/HomeWorks5 _brochure.pdf. Additionally, "Speak, Memory: On Archives and Other Strategies of (Re)Activation of Cultural Memory," which took place at the Townhouse Gallery in Cairo, Egypt, between October 28 and October 30, 2010, tackled issues of cultural memory in the region, specifically in relation to collecting and archiving historical artistic practices. See the "Speak, Memory" brochure, accessed February 9, 2014, http://speakmemory.org/uploads/speakmemory.pdf.
}

${ }^{10}$ See Tony Chakar's The Sky Over Beirut (2009-), an ongoing project, specifically the web page on the Historical City Tour, accessed February 9, 2014, http://www.tonychakar.com. I had the opportunity to participate in one of Chakar's tours, The Sky Over Beirut: Walking Tours of the City, when they were conducted during the "Home Works 5: A Forum on Cultural Practices" in Beirut, Lebanon, from April 21 to May $1,2010$.

11 "Tony Chakar's Historical City Tour," accessed February 9, 2014, http://www.tonychakar.com/Historical -City-Tour. Quoted from the map pin with the numeric label "1."

${ }^{12}$ Mohammad al-Asad, "Amman: How Big Is Too Big?" Urban Crossroads 87 (December 5, 2008), accessed February 9, 2014, http://www.csbe.org/e-publications-resources/urban-crossroads/amman-how -big-is-too-big.

${ }^{13}$ Alev Çinar and Thomas Bender, eds., Urban Imaginaries: Locating the Modern City, (Minneapolis: University of Minnesota Press, 2007). See the essay "Amman Is Not a City: Middle Eastern Cities in Question," by Seteney Shami, which deconstructs the geographical, socioeconomic, cultural, and political spaces in Amman. Additionally, Shami discusses the characteristics of the Ammani terrain, in both the physical and psychological sense, wherein urban planning and identity issues have been the main factor in describing the city.

${ }^{14}$ Mohammad al-Asad, "Cities of the Arab East," Urban Crossroads 5 (May 20, 2004), accessed February 9, 2014, http://www .csbe.org/e-publications-resources/urban-crossroads/cities-of-the-arab-east.

${ }^{15}$ Ibid. 
position of creating infrastructure in a rapid manner, presenting critical debates about urban planning in the modern city. ${ }^{16}$ Amman is currently growing at an exponential rate, encountering fragmentation, decentralization, and urban sprawl; to grasp the physical space of the city vis-à-vis a map has become a difficult task. ${ }^{17}$

\section{The Mapping Experience: Subjectivity and Cognition}

In his 2005 article "Maps, Mapping, Modernity: Art and Cartography in the Twentieth Century," Denis Cosgrove writes that "post-war advances in cognitive psychology challenged many of the assumptions about the transparency of representational images by emphasizing the importance of individual and social perceptions." ${ }^{18}$ Memory plays a large role in these advances in cognitive psychology. The experience of an individual, as well as his or her upbringing, social status, and class, has an immense impact on perceptions, especially in representational images. Maps are inherently part of this mass of imagery related to the translation of the physical world. But to reject the map is not necessarily the rejection of the process of mapping. Maps are the coded two-dimensional illustrations of the city delineated by signs, symbols, lines, and colors, whereas mapping is part of the performance, activity, and engagement of the city. The difference between a map and mapping changes one's relationship to the city from a spectator to participant, passive to active. When one moves through an urban environment, mapping has the benefit of changing one's view of the city, which is dependent on vantage points or perspectives (i.e., inside the maze of a city as compared to that of an omnipresent observation).

In the case of Amman, map production becomes a futile effort in a rapidly changing environment. If a permanent or temporary resident of Amman understands the important markers of the city from a subjective experience, it creates definition and character to an abstract and ambiguous mass of a map that may be slow to catch up with the current environment, whether this map is a paper or digital version. More importantly, as noted in Cosgrove's text regarding perception and imagery, memory has the added flexibility of remaining coded to its user through individual experience, and this subjective knowledge of the interpretation of information is beneficial as it molds to the user's lifestyle and needs. ${ }^{19}$

\footnotetext{
${ }^{16}$ Jordan is at a "strategic location at the crossroads . . . in the Middle East . . . and has had to cope with massive influxes of refugees and migrant workers fleeing conflict areas. In addition to receiving Palestinians, Jordan has also hosted forced migrants from Lebanon during the 1975-1991 civil war and Iraq during and after the 1991 gulf war . . . [T] he 2003 second gulf war, drastically raised the number of Iraqis fleeing and residing in Jordan to an estimated over seven hundred and fifty thousand, increasing the pressure on government authorities, economic, and social infrastructures." See "Jordan," International Organization for Migration, last modified July 2007 (main text) and October 2013 (facts and figures), http://www.iom.int/cms/en/sites/iom/home/where-we-work/ africa-and-the-middle-east/middle-east -and-north-africa/jordan.html.

${ }^{17}$ Seteney Shami in Çinar and Bender, eds., Urban Imaginaries: Locating the Modern City.

${ }^{18}$ Denis Cosgrove, "Maps, Mapping, Modernity: Art and Cartography in the Twentieth Century," Imago Mundi 57, no. 1, 2005, 39. Cosgrove notes in the article's abstract that he "suggest[s] that an examination of art and cartography in the twentieth century should focus on mapping practices rather than on maps," which serves as essential material studies for Mapping Collected Memory and the project's main argument that mapping practices are vital to an inherent understanding of a city, especially one in flux.

${ }^{19}$ Ibid.
} 
In addition, the activity of mapping through memory-an immersion in a particular environment-is an experience between the relationship of bodies in space and one's subjective resonance. This participatory action can serve to inform a navigator as to the type of environment to expect in a previsualization of negotiating space. In Amman, one of the most congested and historical parts of the city is the downtown area, wast al-balad, known locally and informally as al-balad, or the "heart of the city," the city center. ${ }^{20}$ Even a reference to an urban center as the heart of a city, implies an intrinsic understanding of that space, and encapsulates the metaphorical pulse of al-balad without the aid of a formal map. One's personal experience to this area is heightened by the knowledge of this information. To navigate a city, to walk or drive a city, is to fully participate in the noise, confusion, congestion, stagnation, bustle, movement, fluidity, and stillness of an urban entity. On a map, a satellite image (e.g., Google Maps) showing an area of mass congestion is translated and reduced to a series of topographical and geographical demarcations. But what is it like to actually stand within the area, and to be surrounded by a certain kind of aura and space?

\section{Markers in the Landscape}

For the sake of this short written account, it is easier to comment on the commonalities observed during guided tours than to tease out all the singular types of landmarks. From tours into the urban environment, patterns exist regarding the types of landmarks used in navigation. The common landmarks, both in walking and driving trips, include heavily frequented buildings in the area, such as shopping centers and marketplaces, hospitals (figs $1,2,3,4$ ), banks (fig. 1), and religious spaces (fig. 5). Large hotels that stand towering over the average height of the short Ammani building become part of the regular lexicon of the city as well. Notable hotels are especially part of the vocabulary of the city, which include the Grand Hyatt, the Four Seasons, the Sheraton (fig. 2), and the InterContinental (fig. 6). A bit of speculation could lead one to the internationalization of the Ammani environment, which finds itself with a large community of expatriates. The act of using major international hotels as landmarks, which often bear names in English, the typical default language in Amman for non-Arabic speaking residents, is a process that aids memory.

Interestingly, bridges (fig. 7), open spaces (fig. 8), and construction sites (figs 9, 10, 11) serve as visual markers to travelers. These sites are akin to an urban cairn in the road. Like a cairn, which is a unique and unnatural mound of rocks created for the sole purpose of establishing a node and directional point, empty lots and the odd visual geometry of construction zones contain interesting configurations, cranes, and objects that induce a viewer to establish a landmark. As a result, residents have an awareness of the exponential growth of Amman, and an inherent understanding of the changing city.

The most important and widely recognized feature in the Ammani navigational system is the roundabout, referred to in the city as a "circle." The western part of the city contains one large road or artery labeled Zahran Street, and organized on this route are a series of eight roundabouts informally labeled as the First Circle through Eighth Circle (figs 1, 2). Any individual wishing to navigate Amman on the western side can use the closest roundabout to their desired end point. Once there, the navigator might utilize landmarks near and around the circle to their final destination. It should be noted that there are additional roundabouts

\footnotetext{
${ }^{20}$ In Arabic, the word al-balad literally translates to "the country."
} 
throughout the city (e.g., Paris Circle and City Circle) that are off of the throughway of the numeric system, and prove to be just as useful in navigational methods.

The common characteristic regarding the use of these landmarks can be drawn back to one's relationship to the city. If one lives in a specific neighborhood, the landmarks are particularly fleshed out in terms of imaging, making use of a wider range of markers in the area.

\section{The Image-Making of the City}

Photography's relationship to memory has been a tenuous one, and subject of debate, in recent years. Much like photography, memory is a subjective experience: changing and shifting over the course of time. If one is to compare the brain and a representational object, there is much fodder for observational study. The posterior hippocampus, the portion of the human brain responsible for memory, also "stores spatial representations of the environment . . . is plastic, and undergoes structural change depending on the amount of navigational experience." ${ }^{21}$ Is this dissimilar to the map and the photograph, which capture a particular scene but are experienced through the subjectivity of time, place, and viewer, as well as maker? In the case of the color photograph, the object itself, which is literally made from plastic, is doomed to fade and disintegrate, changing the aesthetic read of its subject matter.

How do these images capture the essence of the navigational process? Mainly, these informal guided tours are time-based performative trips, with digital video footage serving as the primary element of documentation, as well as reference and observational material. Navigating back to specific landmarks requires a memorization of the guides' tour routes. So, effectively, the process of returning to a particular spot to photograph these markers-a guide's subjective interpretation on imaging landmarks-requires an exercise in remembrance or re-memorization of the route. Therefore, the photographic representations of landmarks are tapped into the memory-focused component of the project, as the photographic act is "a reflexive medium that exposes the stakes of historical study by revealing ... [its] constructed nature of what constitutes historical evidence. ${ }^{\prime 22}$ The images presented in Mapping Collected Memory rely extensively on the compositional constructions and considerations of urban representation, and much like the city and memory-the plasticity that occurs through all of these facets.

The large-format camera was selected to capture the landmarks for two distinct reasons. Firstly, the camera has the ability to create standard movements, such as tilt, shift, swing, rise, and fall, used for landscape and architectural photography to plumb converging lines. However, this can also create the opposite effect of skewing and distorting the image, thereby drawing attention to important details in various landmarks through the focal points or effectively distorting them. Secondly, in regard to distortion, most of the images are produced with the aperture f/5.6, the largest aperture available on the particular lens used for this project, which creates an awareness of the image's surface via shallow depth of field.

\footnotetext{
${ }^{21}$ Gillian Cohen and Martin A. Conway, eds., Memory in the Real World, 3rd ed. (Hove: Psychology Press, 2008), 176. The writing serves as a practical guide to everyday memory. The chapter on "Memory for Places: Routes, Maps, and Object Locations," co-authored by Alastair D. Smith and Gillian Cohen, was particularly useful in my research for Mapping Collected Memory.

22 Jennifer Tucker, "Entwined Practices: Engagements with Photography in Historical Inquiry," in collaboration with Tina Campt, History and Theory 48, no. 4, (December 2009): 3. Here Tucker critically examines photographs as historical objects.
} 
The effect is purposefully subtle, a kind of anti-aperture f/64 statement in regard to representational imagery, specifically a resistance of that eponymous group's motives "to present the camera's 'vision' as clearly as possible." ${ }^{23}$

Essentially, the resulting images, outside of their context, are banal. The images are external to the mind's faculties of memory. They do not reference or add up to much other than solitary images of an environment, and are external to the use of the narration that provide their very existence: a subjective context to navigate the city. These images are stark, mostly devoid of human presence; landmarks in isolation with clear skies. They are imaged at specific times of day, always early on Friday mornings-the start of the weekend in Jordan-when the streets tend to be quiet and still. They are large-scale images at forty inches (101.60 centimeters) in height with parenthetical titles. When lined up in a complete series, there is an inclination to create leaps, nodes, or stops on the print surface: a tally of a specific destination. But the images, as a whole, lead to a nowhere "less cognate with written history than with the raw materials of written history: traces of lived experience." ${ }^{24}$ These landmarks are so personalized that the representation or imaging of them seems to crumble, fade, and fall apart. The images require narration of their experiences, an explanation of the spaces, as they are completely detached from the navigational process but clearly reference "an experience of a past exactly at the instant it crosses into an indeterminate future."25 They are not presentations of how to navigate in an unfamiliar city, but a call to become acquainted with its streets through conversations, experiential learning, and a relationship to the city, which requires measured patience and time.

There is an awareness of an obsolescence of technology: the application of a largeformat analog camera, a heavy piece of equipment, requiring a vehicle to navigate to photographic sites, as well as twenty to thirty minutes to set up and compose shots of the landmarks. Something so sturdy and stationary seems bound to an architectural element made of stone. Much like the map, the images are subject to obsolescence and mutability over time. Already four years old, printed on chromogenic paper, their relevance is waning. A conscious decision has been made to utilize color photographs with an expiration date, avoiding archival pigment prints. The memorization of the city is a malleability encapsulated in the mind-not a static image-created with eventual decay. The photographic process is flawed from the start, but is deeply embedded in an urge to learn the city's streets, eventually expanding the memory's knowledge through the plasticity of experiential practice.

\section{Conclusion}

What is there to learn by comparing the relationship of the photographic document, a representational object acting as metaphor for a contemporary city, to navigational processes? In the act of navigating Amman, while maps provide a user with a generalized

\footnotetext{
${ }^{23}$ Lisa Hostetler, "Group f/64." Quoted from the Heilbrunn Timeline of Art History (New York: The Metropolitan Museum of Art, 2000-), last modified October 2004 (main text), http://www.metmuseum .org/toah/hd/f64/hd_f64.htm.

${ }^{24}$ Alan Trachtenberg, "Through a Glass, Darkly: Photography and Cultural Memory." In the themed issue "Collective Memory and Collective Identity," Social Research 75, no. 1, (Summer 2008): 121-22. Trachtenberg discusses the relationship between the subjective and objective views of memory through photography.

${ }^{25}$ Ibid., 119.
} 
overview of the city, landmarks incorporating memory-based navigational methods should not be overlooked. Amman is currently growing at an exponential rate, and to grasp the physical space of the city through an inside-out navigational perspective becomes ever more important. Landmarks are part of the vocabulary, civic engagement, and urban growth of Amman, but more importantly, they are the subjective experiences incorporated into the navigational process. With Amman's urban sprawl and a decentralization of the major areas throughout the city, it is important to recognize the benefits of a personalized approach to understanding the urban fabric, which serve to narrate the experience of residents through a series of explorations, and give voice to the city from a subjective viewpoint. A photograph can aid in this process, not as an agent of history or as a historical document, but as a metaphor to call into question the static nature of urban entities and the proposed relationship to representational materials. 


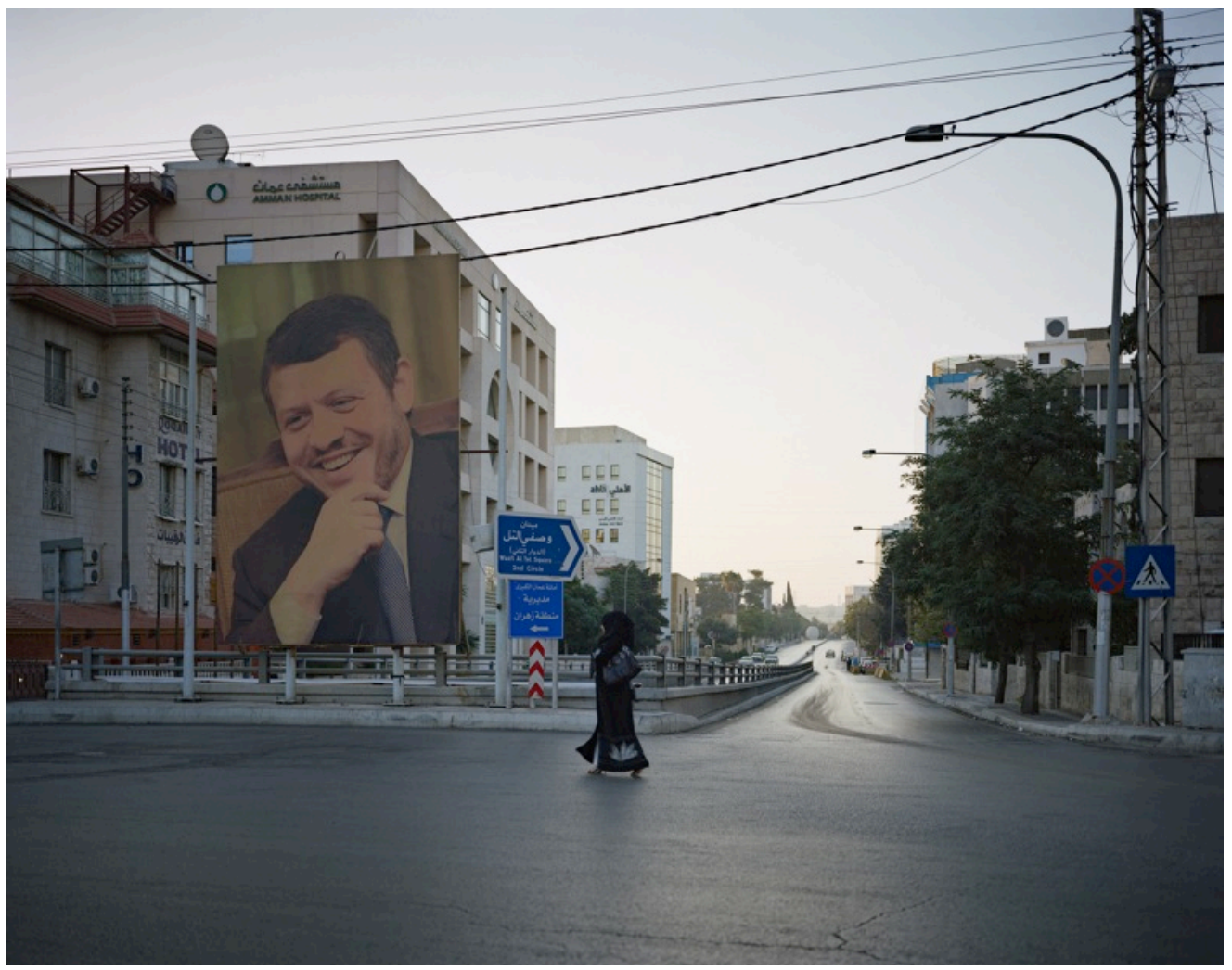

Figure 1

Regina Mamou, Untitled (Third Circle) from the series Mapping Collected Memory, 2009-2010. Digital C-print, $40 \times 50$ in. $(101.60 \times 127 \mathrm{~cm})$. 


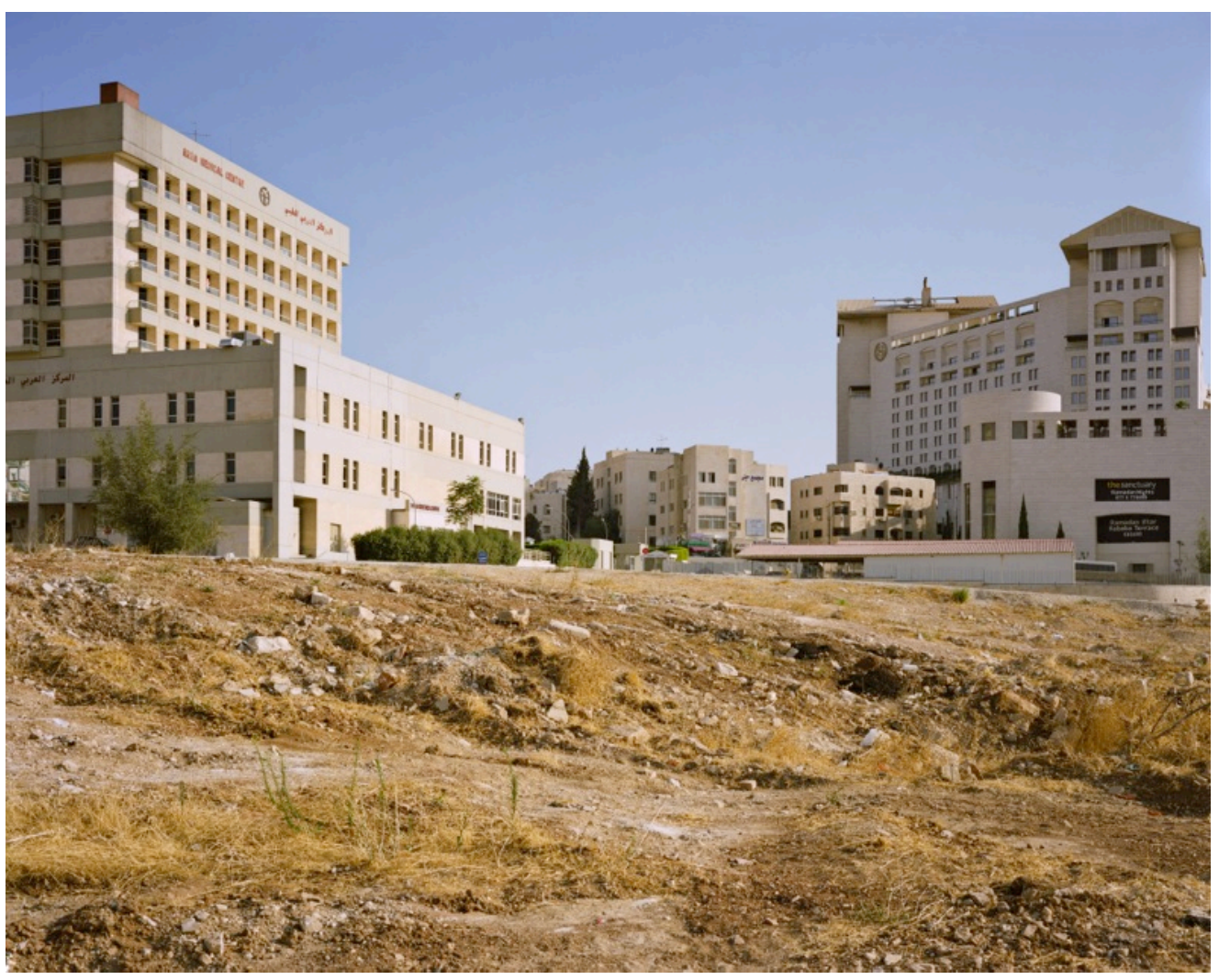

Figure 2

Regina Mamou, Untitled (Near Fourth Circle) from the series Mapping Collected Memory, 2009-2010. Digital C-print. $40 \times 50$ in. $(101.60 \times 127 \mathrm{~cm})$. 


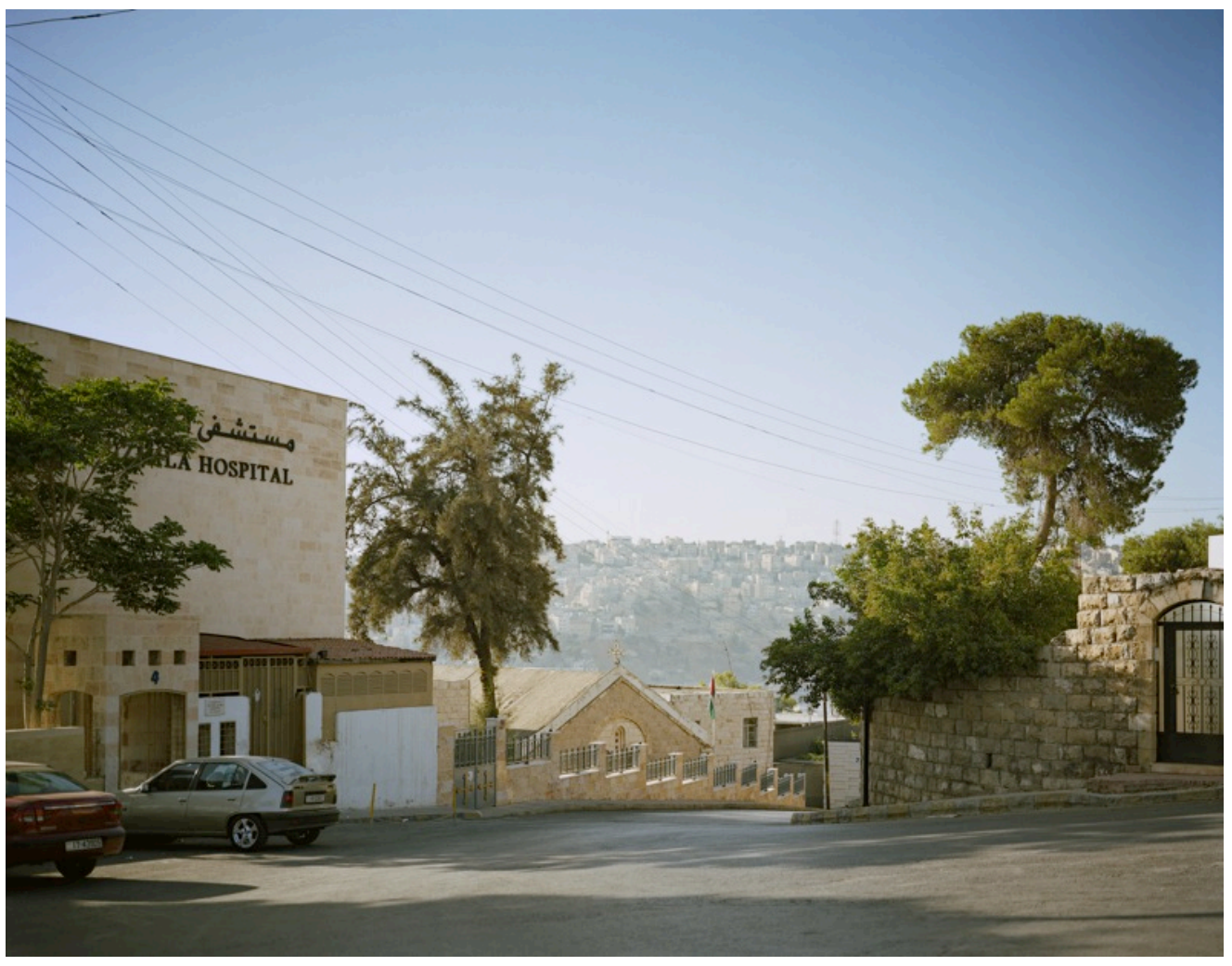

Figure 3

Regina Mamou, Untitled (Luzmila Hospital) from the series Mapping Collected Memory, 2009-2010. Digital C-print. $40 \times 50$ in. $(101.60 \times 127 \mathrm{~cm})$. 


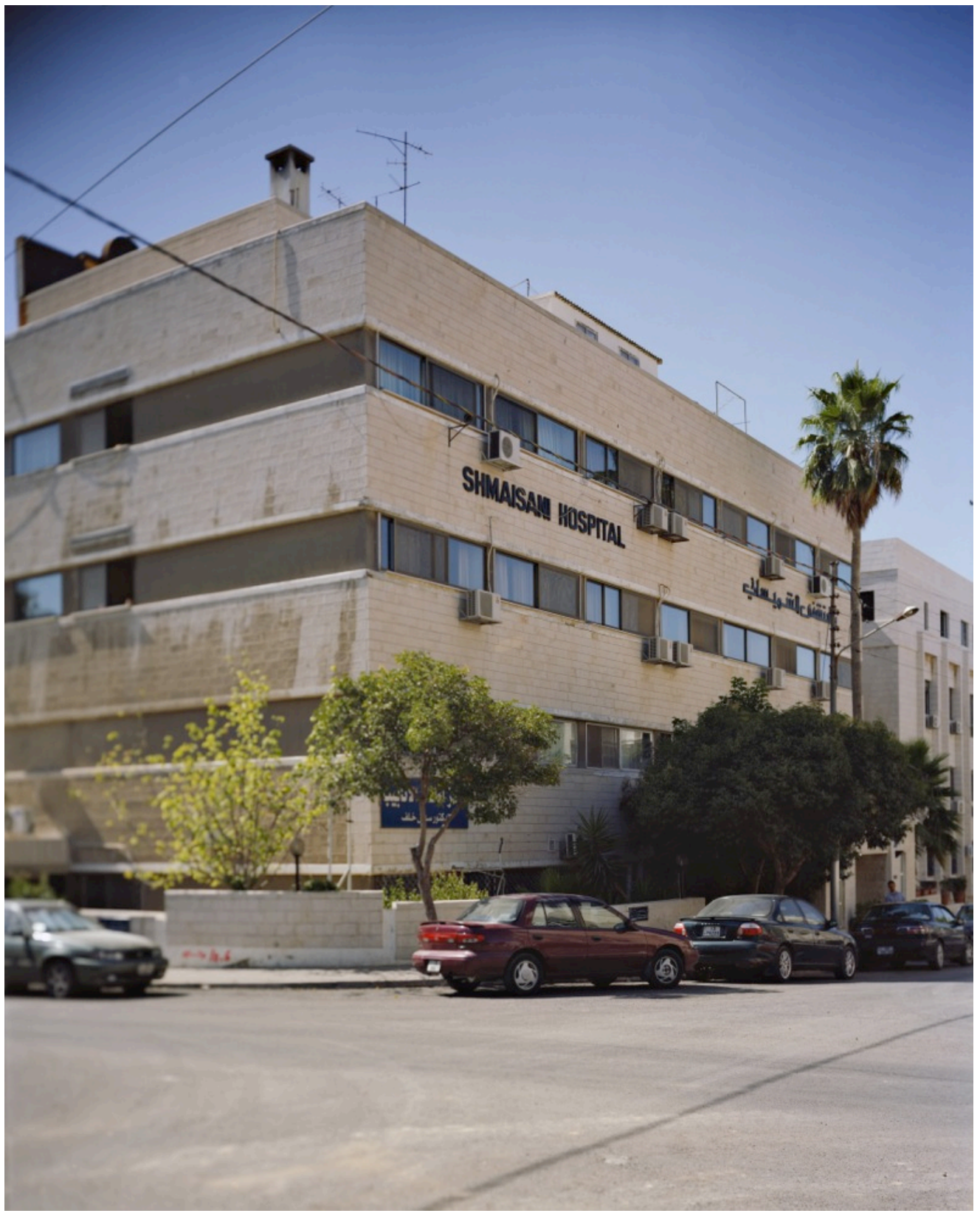

Figure 4

Regina Mamou, Untitled (Shmeisani Hospital) from the series Mapping Collected Memory, 2009-2010. Digital C-print. $40 \times 32$ in. $(101.60 \times 81.28 \mathrm{~cm})$. 


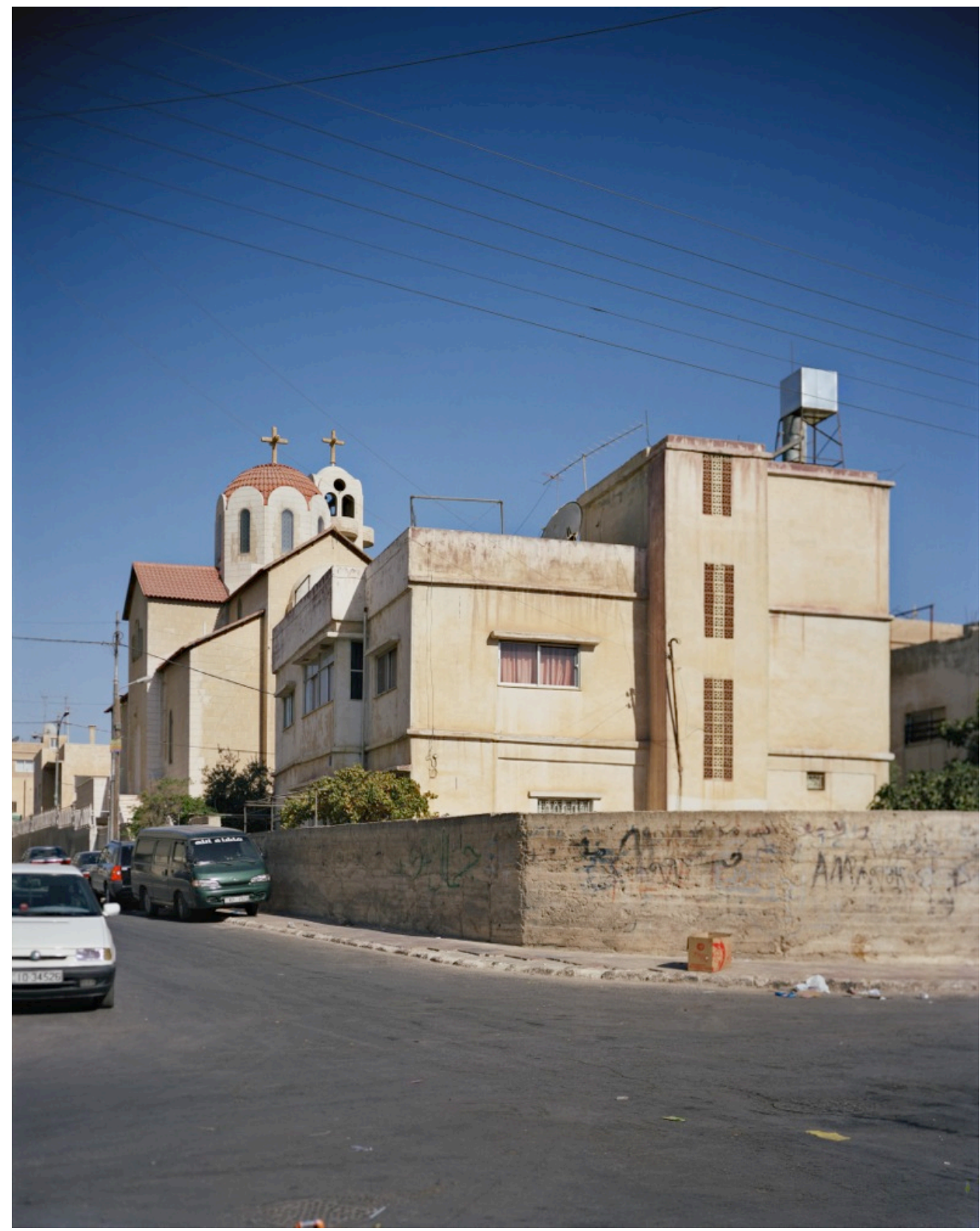

\section{Figure 5}

Regina Mamou, Untitled (Street Corner, Hashimi) from the series Mapping Collected Memory, 20092010. Digital C-print. $40 \times 32$ in. $(101.60 \times 81.28 \mathrm{~cm})$. 


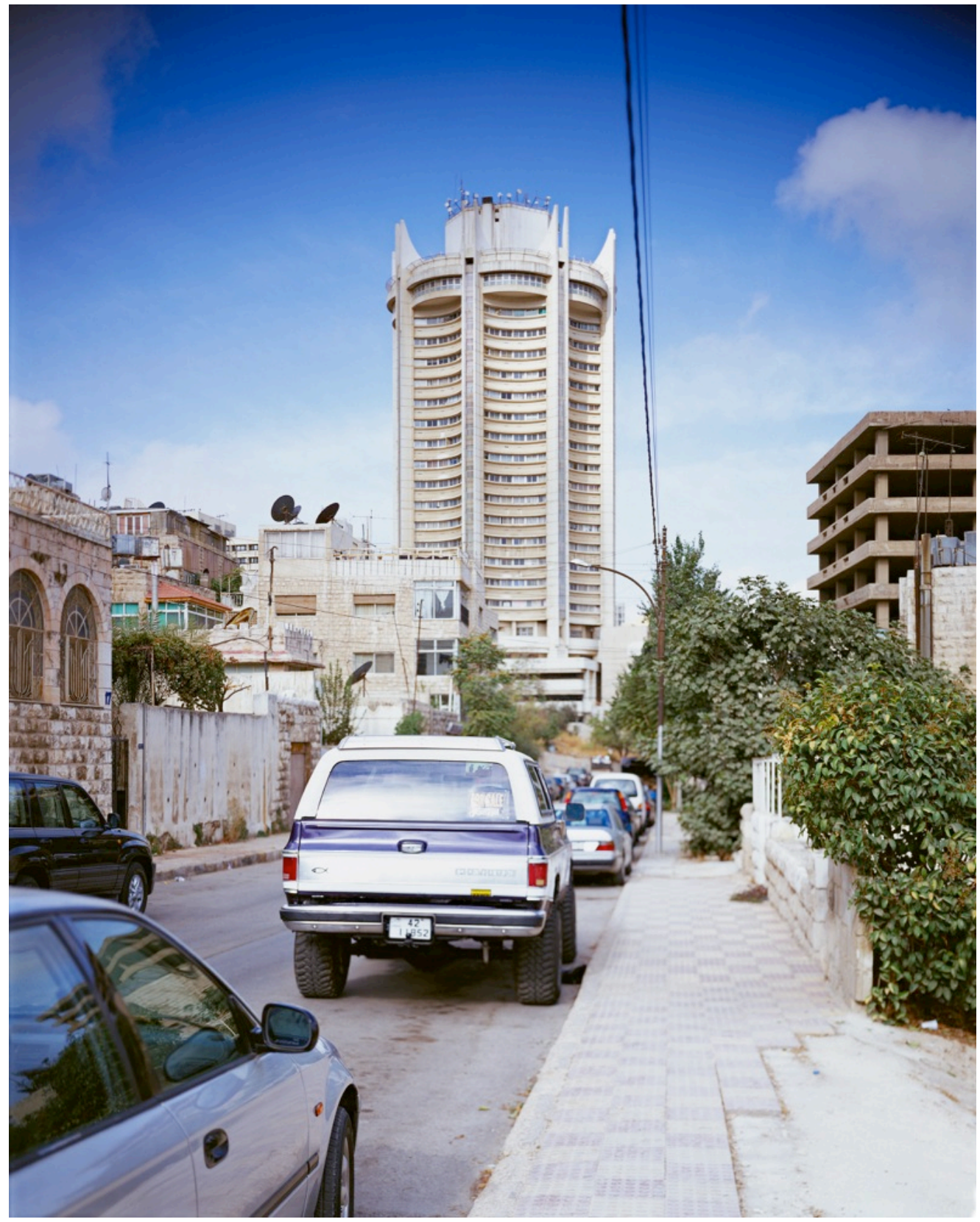

Figure 6

Regina Mamou, Untitled (InterContinental) from the series Mapping Collected Memory, 2009-2010. Digital C-print. $40 \times 32$ in. $(101.60 \times 81.28 \mathrm{~cm})$. 


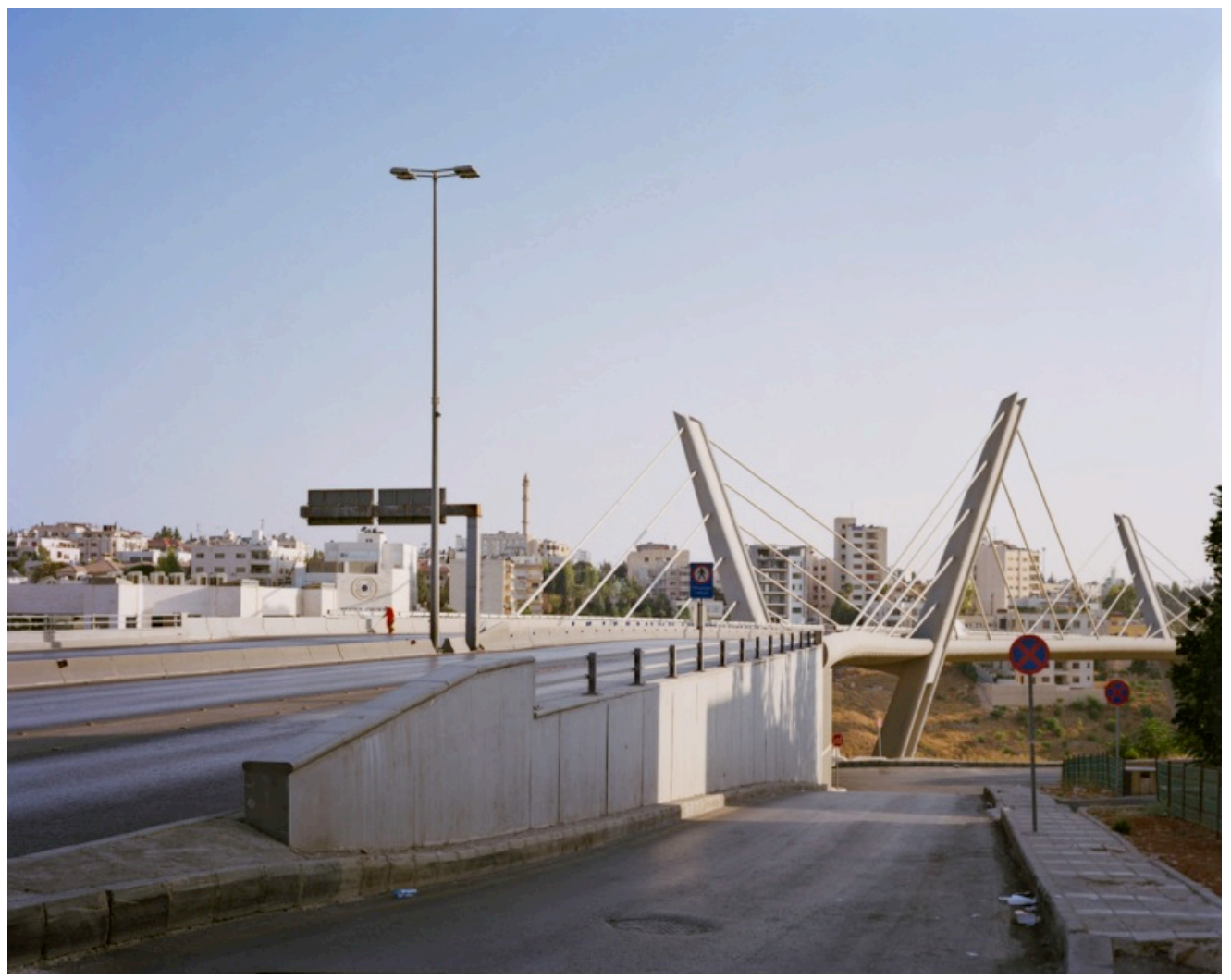

\section{Figure 7}

Regina Mamou, Untitled (Abdoun Bridge) from the series Mapping Collected Memory, 2009-2010. Digital C-print. $40 \times 50$ in. $(101.60 \times 127 \mathrm{~cm})$. 


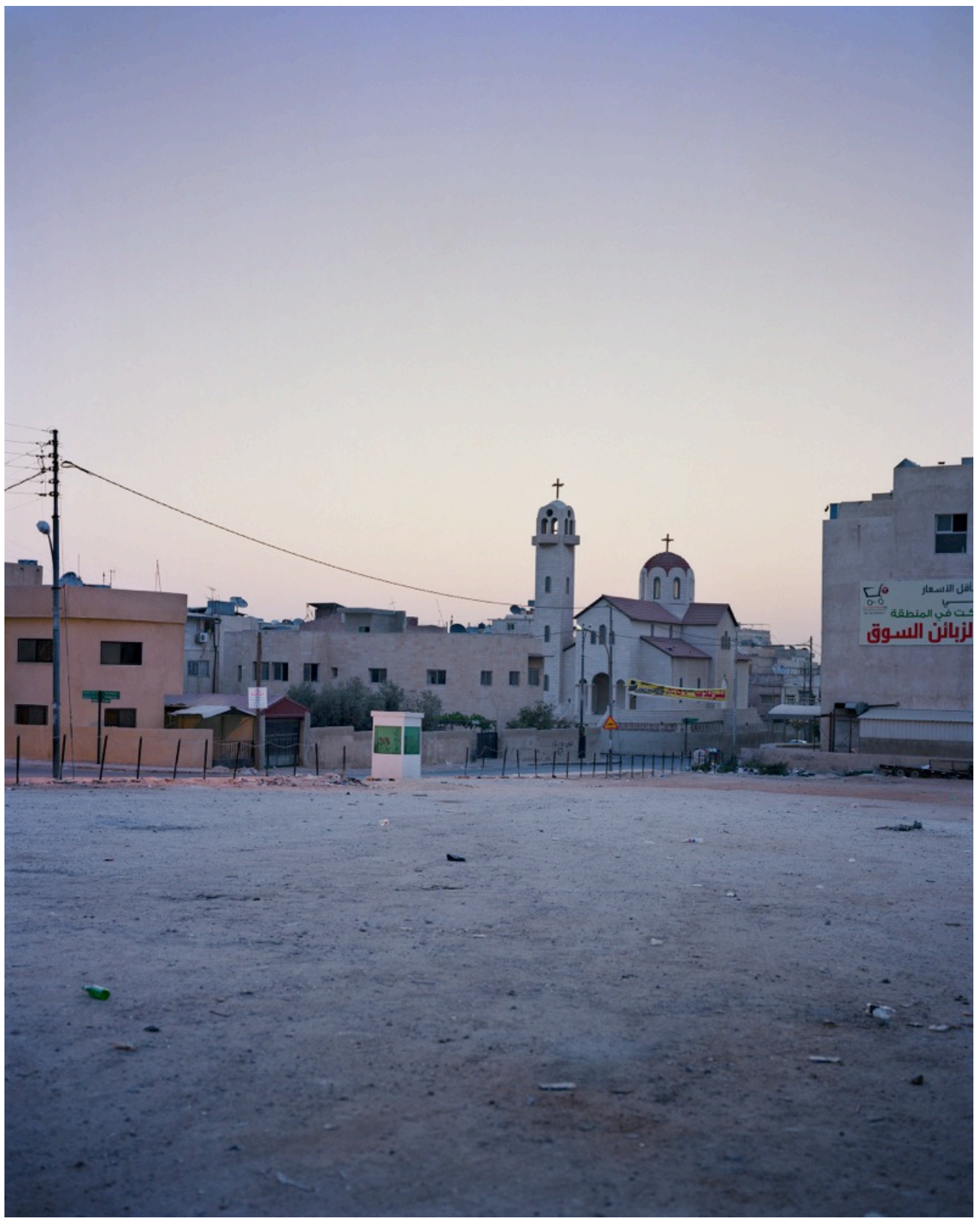

\section{Figure 8}

Regina Mamou, Untitled (Dawn, Hashimi) from the series Mapping Collected Memory, 2009-2010. Digital C-print. $40 \times 32$ in. $(101.60 \times 81.28 \mathrm{~cm})$. 


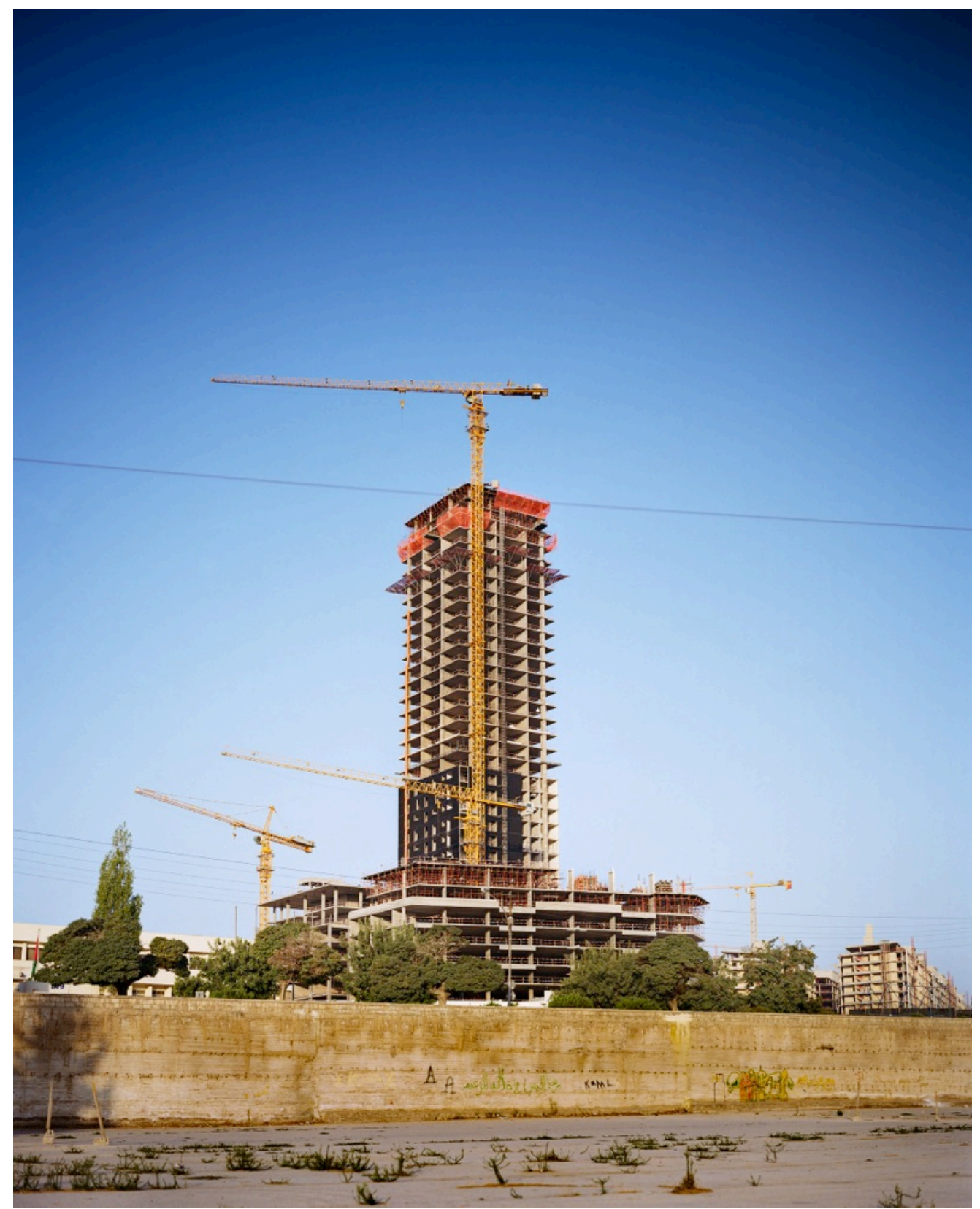

\section{Figure 9}

Regina Mamou, Untitled (Abdali's Plan) from the series Mapping Collected Memory, 2009-2010.

Digital C-print. $40 \times 32$ in. $(101.60 \times 81.28 \mathrm{~cm})$. 


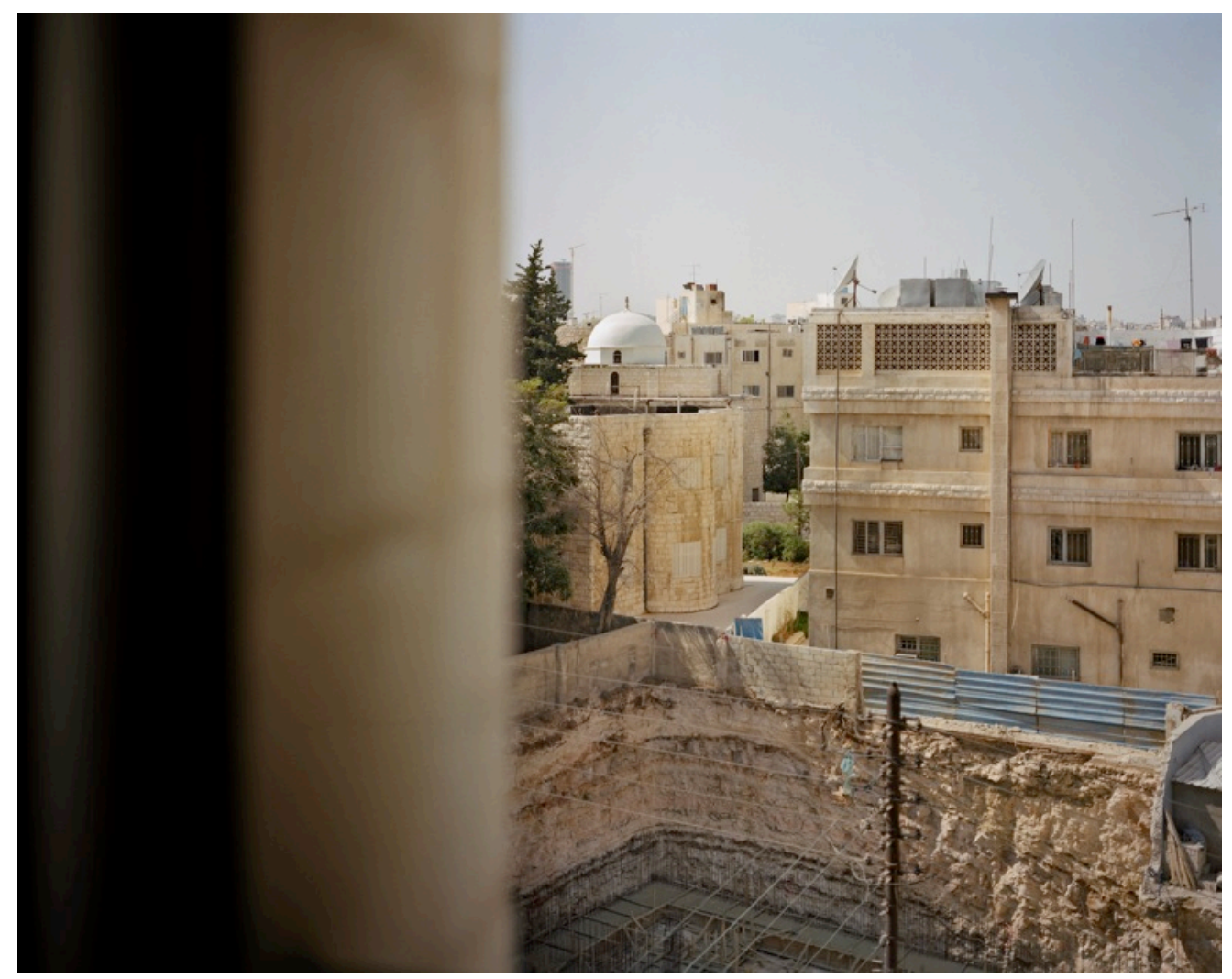

Figure 10

Regina Mamou, Untitled (Site \#1) from the series Mapping Collected Memory, 2009-2010. Digital C-print. $40 \times 50$ in. $(101.60 \times 127 \mathrm{~cm})$. 


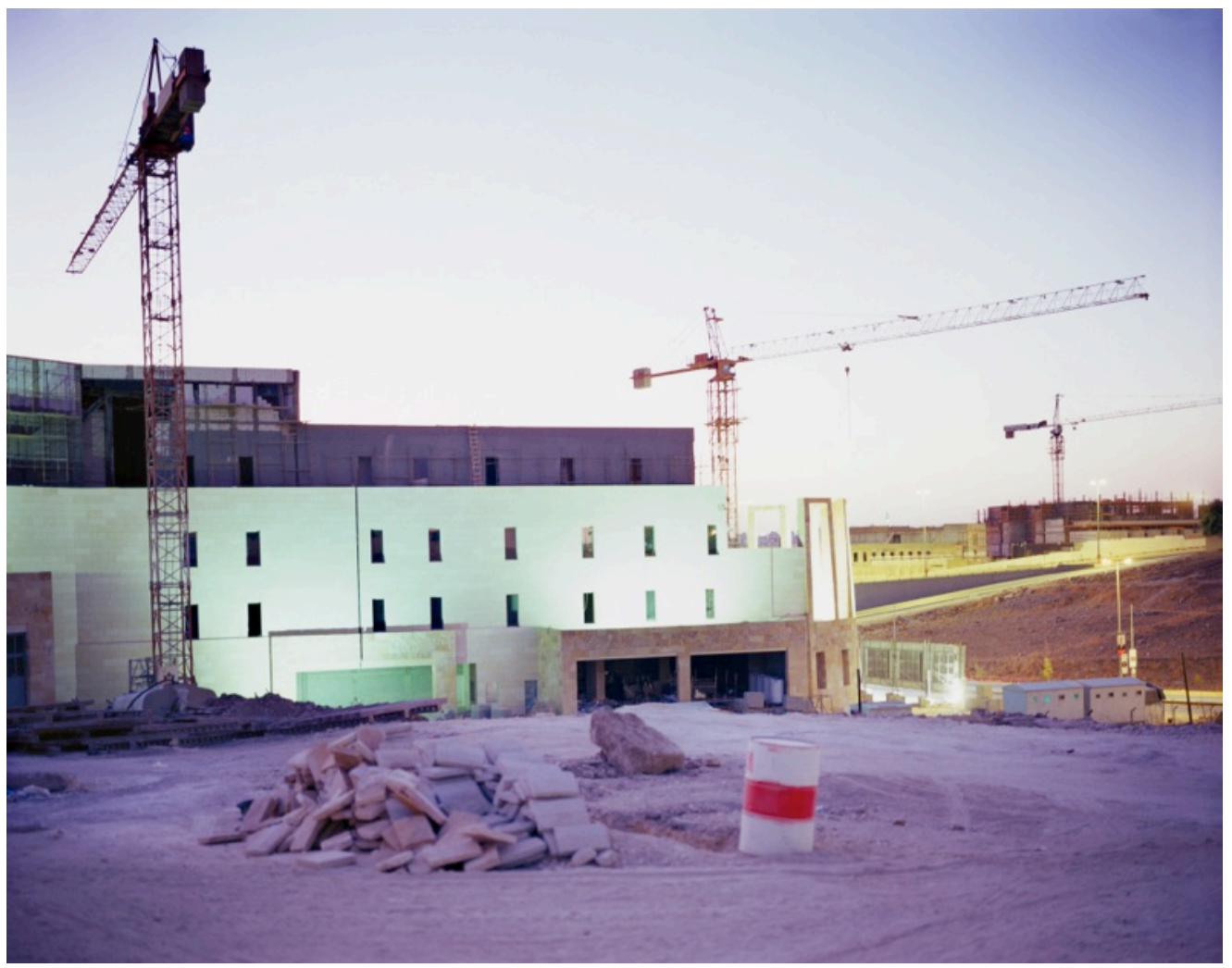

Figure 11

Regina Mamou, Untitled (Site \#2) from the series Mapping Collected Memory, 2009-2010.

Digital C-print. $40 \times 50$ in. $(101.60 \times 127 \mathrm{~cm})$. 


\section{(oc) EY-NC-ND}

This work is licensed under a Creative Commons Attribution-Noncommercial-No Derivative Works 3.0 United States License.

\section{ULIS D-SulR}

This journal is operated by the University Library System of the University of Pittsburgh as part of its D-Scribe Digital Publishing Program, and is co-sponsored by the University of Pittsburgh Press. 